\title{
REPRESENTAÇÃO DISCURSIVA NO AMBIENTE ECOLINGUÍSTICO NA FRONTEIRA BRASIL/VENEZUELA
}

\author{
(Discoursive representation of the ecolinguistic environment \\ at the Brazilian-Venezuelan border)
}

Maria Ivone Alves da Silva ${ }^{10}$

(Universidade Estadual de Roraima-UERR)

\begin{abstract}
The configuration of the border regions in the Americas comes from the European requirements for new products and raw materials. Remounting to the historical past, there is a real demand exists for conducting studies and research aimed at understanding the linguistic environment characterizing the contacts of people in aspects involving the language in relation to the natural environment and socio-historical, as in the case of the Brazil / Venezuela border. One of the concerns that are relevant in this work requires the consideration is whether the situation of language contact influences the conformation of environment of the Brazil / Venezuela determining a close relationship, the intensity of which is conditioned by relational links that are established between people. In addition, this study aims to characterize the state of the contact people in the linguistic ecosystem Brazil / Venezuela, by recognizing the nature of the factors that influences the outcome of the contact situations, basing on the elements of Ecolinguistics in accordance with Couto (2007, 2009). The subjects are four "residents of the border" Pacaraima-Brazil / Santa Elena de Uairén-Venezuela. Considering that the discursive representations are full of statements that can express all kinds of feelings, and starting from

10. Doutoranda em Letras Neolatinas pela Universidade Federal do Rio de Janeiro (UFRJ) e Mestra em Letras Neolatinas pela mesma universidade. Professora Licenciada em Letras, Especialialista em Metodologia do Ensino de Língua Portuguesa e Literatura e Especialista em Gestão Escolar. Docente da Rede Pública Estadual de Roraima e Pesquisadora I da Capes - Programa de Formação de Professores-PARFOR, Unidade Universidade Estadual de Roraima (UERR).
\end{abstract}


the principle that the subject speech carries fragments of this reality, it is possible to visualize the different levels of interaction that occur made between subjects at that border. It is also possible to say that there is a unique ecosystem that influences mutually whose people they meet in a reciprocal manner, communicating through language characteristics of the place and that, on principle, could be called linguistic ecosystem "provisional".

Keywords: Ecolinguistics, Brazil / Venezuela border, discourse

\section{RESUMO}

A configuração das regiões fronteiriças no Continente Americano surge a partir das necessidades europeias por novos produtos e matérias primas. Remontando ao passado histórico, verifica-se existir uma demanda real pela realização de estudos e pesquisas voltadas para a compreensão do ambiente linguístico caracterizando os contatos de povos nos aspectos que envolvem a língua em relação ao ambiente natural e sócio-histórico, como no caso da fronteira Brasil/Venezuela. Uma das preocupações pertinentes que se impõe à reflexão neste trabalho é se a situação de contato linguístico influi na conformação do ambiente de fronteira Brasil/Venezuela determinando uma relação de proximidade, cuja intensidade é condicionada pelos vínculos relacionais que se estabelecem entre os povos. A par disto, esta pesquisa tem como objetivo caracterizar a situação de contato de povos no ecossistema linguístico Brasil/Venezuela, por meio do reconhecimento da natureza dos fatores que influenciam no resultado das situações de contato, fundamentando-se nos elementos da Ecolinguística, em conformidade com Couto (2007, 2009). Os sujeitos são quatro "moradores da fronteira" Pacaraima-Brasil/Santa Elena de Uairén-Venezuela. Considerando-se que as representações discursivas estão repletas de enunciados que podem expressar os mais variados tipos de sentimentos, e partindo-se do princípio de que o discurso do sujeito traz consigo fragmentos dessa realidade, é possível a visualização dos diversos niveis de interação que ocorrem entre os sujeitos constituídos nessa fronteira. É possível afirmar também que se constitui aí um único ecossistema que se influencia mutuamente cujos povos se atendem de forma recíproca, se comunicando através das línguas características do lugar e que, por princípio, poderia ser denominado de ecossistema linguístico "provisional".

Palavras-chave: ecolinguística, fronteira Brasil/Venezuela, discurso. 


\section{Introdução}

As fronteiras interpaíses são consideradas áreas estratégicas pelos Estados Nacionais. A faixa fronteiriça brasileira compreende os limites com a Colômbia, Peru, Bolívia, Paraguai, Argentina, Uruguai, Guiana Francesa, Suriname, República Cooperativa da Guiana e a Venezuela. Essas fronteiras envolvem onze estados brasileiros, dos quais Roraima faz parte, caracterizado por situações de contato das línguas europeias de colonização entre as línguas portuguesa, a língua inglesa e língua espanhola.

Remontando ao passado histórico, desde o período colonial até a contemporaneidade, verifica-se que as diretrizes políticas dos Estados Nacionais para as regiões fronteiriças ainda se restringem, em grande parte, aos interesses de ocupação e defesa estratégica das fronteiras. Contudo, a estratégia na direção da integração interpaíses com a organização em blocos econômicos e políticos, faz surgir o interesse pelas culturas regionais e pelas culturas dos povos fronteiriços. Uma iniciativa de integração dessa natureza está na política brasileira das diretrizes educacionais, e um dos resultados é a oferta do curso de Língua Portuguesa como Língua Estrangeira - PLE, pela Universidade Estadual de Roraima. O curso de PLE é oferecido no campus de Pacaraima, fronteira com o município de Santa Elena de Uairén, na Venezuela, onde localizamos os sujeitos colaboradores desta pesquisa.

Outra demanda crescente nessa direção de integração está na realização de pesquisas direcionadas à compreensão do ambiente linguístico em suas diversas manifestações, a fim de caracterizar os contatos dos povos nos aspectos que envolvem a língua em relação ao ambiente natural e sócio-histórico.

$\mathrm{O}$ reconhecimento da natureza dos fatores que influenciam no resultado das situações de contato estabelecidos nesses ecossistemas linguísticos é importante e pode auxiliar a compreender as interações que caracterizam essa situação específica de contato. Pressupõe-se, assim, que a situação de contato exerce influência recíproca nas relações mantidas e, portanto, pode interferir no posicionamento discursivo da população das regiões fronteiriças. Nessas circunstâncias, conforme 
observa Couto, (2007, p. 17), é possível supor que possa haver uma tendência ao surgimento de uma única comunidade de fala, emergida gradualmente ao longo do processo histórico da evolução dessa fronteira.

\section{Ambiente fronteiriço Brasil/Venezuela}

A evolução do conhecimento técnico-científico experimentado pelos Estados Nacionais facilitou o dinamismo das tecnologias e equipamentos de transportes e comunicações e aumentou consideravelmente o volume e os movimentos dos deslocamentos interfronteiriços. Esse processo trouxe à tona a porosidade das fronteiras nacionais, étnico-culturais e identitárias, permitindo as trocas materiais e simbólicas, onde se confrontam indivíduos e culturas muito diferentes. Dão-se aí relações marcadas por práticas de deslocamento que devem ser percebidas como constitutivas de significados culturais ao invés de serem apenas uma extensão ou transferência desses significados.

O espaço fronteiriço entre o Brasil e a Venezuela também vem sendo profundamente impactado em virtude das novas tecnologias de transporte e comunicação intensificando os fluxos transfronteiriços de mercadorias (legais e ilegais), de pessoas (turistas, moradores de fronteiras, imigrantes, trabalhadores migrantes), bem como fluxos imateriais e simbólicos (bilinguismo, portunhol) em que as culturas e as identidades transcendem seu lugar de origem e se hibridizam a ponto de ser cada vez mais difícil identificar suas origens (Rodrigues 2011, p.197).

A compreensão da origem desse fluxo de relações que hoje se processa no âmbito fronteiriço Brasil/Venezuela perpassa pelo entendimento da formação das fronteiras interpaíses na América do Sul, surgidas como resultado do processo colonizador europeu, no século XVI. Duas nações, principalmente Espanha e Portugal, são as protagonistas do processo que resultou na demarcação da primeira 
fronteira no continente americano do sul, representada pelo Tratado de Tordesilhas.

Nesse contexto do passado colonial na América do Sul temse o fundamento para que os países se emancipassem, apesar das dificuldades surgidas na interpretação e demarcação de zonas pouco povoadas e de acesso difícil como as florestas da Amazônia e os picos da Cordilheira andina. Um movimento que se destaca e marca a definição da formação das fronteiras foram as Bandeiras, irradiadas a partir de São Paulo no Sul e no Norte por Belém, onde as penetrações e caminhos se faziam não a pé, mas em canoas, sendo a responsável primeira pela ocupação da Amazônia (Martin, 1992, p. 82), pelo lado brasileiro da Amazônia.

No Brasil colonial todo um conjunto de atividades e relações socioeconômicas vão se destacar desde a produção de cana-deaçúcar e mineração, passando por eventos como a escravidão, missões, cidades costeiras, miscigenação, tudo isso corroborando para várias situações de contato linguístico entre os lusos brasileiros e também desencadeando um tipo de contato entre Brasil/Venezuela.

A formação do espaço sócio-histórico da fronteira Brasil/ Venezuela foi se fazendo ao longo do processo de colonização europeia na América do Sul. Ele sedimenta um conjunto de traços e características geopolíticas e culturais por que são refletidas na língua, por exemplo, nos nomes dos rios, de lugares, plantas, arvores, resultando num ambiente físico que proporciona um espaço de enunciação rico em representações discursivas e com características peculiares. Existe nesse ambiente como que, de acordo com Diegues (1980), um tipo de organização social cujos relacionamentos com o espaço geográfico - a terra, a fauna, a flora - é recriado no cotidiano das populações tradicionais, ou não, e que dão significado a tudo o que acontece entre a esfera humana e a natural. Baseado em Rodrigues (2006), o estudo dessa região fronteiriça Brasil/ Venezuela se dá não somente em virtude de ser a fronteira um lugar singular de trânsito, mas também de encontros culturais e de jogos de identidades. Essa percepção da fronteira como lugar de contato remete à ideia de movimento e de trocas, de relações culturais 
e linguísticas o que permite uma compreensão das dinâmicas das migrações sul-americanas e do processo de integração entre essas duas nações.

Esse processo de formação da fronteira Brasil/Venezuela é dinamizado principalmente em face da fusão das coroas portuguesa e espanhola no período de 1580 e 1640 . Neste período, os portugueses direcionaram sua penetração para o interior do continente americano, descobrindo o ouro de Minas Gerais, introduzindo o boi e a implantação de currais e as Bandeiras descendo os rios Tietê, Paraná, Paraguai e Prata, subindo o Rio Amazonas e seus tributários. Na ocupação do interior do país houve o encontro com outras nacionalidades, especialmente na Amazônia, o que levou à determinação de se fundarem fortificações e guarnições militares em todo o norte e oeste do país (Freitas, 1991, p. 12).

Na Amazônia brasileira, a colonização portuguesa rumo ao embrião formador da atual fronteira com a Venezuela surge a partir do Rio Negro e do Rio Branco no século XVII. Embora outras tentativas de ocupação tivessem ocorrido através de holandeses, ingleses e espanhóis, nesse período coube efetivamente aos portugueses a fixação e posse a partir de 1639 .

Por outro lado, o embrião do processo de ocupação e formação do espaço amazônico da Venezuela e consequentemente do estado de Bolívar nasce com a ocupação hispânica na Amazônia venezuelana principalmente a partir do século XVIII, na época das expedições de José Solano com o propósito de estabelecer a demarcação dos territórios que estavam sob a jurisdição das coroas portuguesas e espanholas. A estratégia de José Solano era fazer cumprir o que havia sido estabelecido pelos Tratados e construir fortificações com o propósito de exercer o controle sobre as embarcações e expedições que chegassem à região, especialmente as que proviessem das colônias portuguesas em direção ao sul do Brasil. Ele é considerado precursor e responsável pelo início da ocupação hispânica na Amazônia venezuelana (Boadas, 1983, p. 86-88). 


\section{Ecossistemas linguísticos fronteiriços}

A Ecologia vem dando lugar a uma série de abordagens científicas desde a sua criação pelo biólogo alemão Ernst Haeckel na segunda metade do século XIX, mais especificamente em 1866, na obra Generelle Morpfologie der organismen, para designar uma nova área de conhecimento voltada à compreensão que extrapola, já em muito, a vertente puramente biológica. Segundo Branco (1987, p. 9); Dajoz (1983, p. 13-16) e Couto (2007), a Ecologia está presente nas ciências naturais, humanas, sociais, políticas, econômicas, na cultura e nas artes, nas filosofias, e mais recentemente na Ecolinguística.

Partindo do ponto de vista de uma comunidade biológica, considerada o conjunto formado por todos os seres vivos que convivem em um determinado território, o conceito de ecologia extrapolou suas origens nas ciências biológicas e enveredou pelos domínios das ciências humanas e sociais, exatas, bem como nas artes, no pensamento filosófico e nas tradições, ou seja, em todos os campos dos saberes humanos. O termo vem do grego oikos $=$ casa e logos $=$ estudo, e sugere o estudo do "lugar onde se vive", pensado em diversas escalas - do lugar que moramos à ecosfera - este compartilhado com bilhões de outros seres vivos, e levando-se em conta toda a diversidade de aspectos materiais, biológicos, humanos e sociais.

Para esses autores, a Ecologia transbordou os limites da Biologia, diversificou-se e passou a integrar as mais diversas disciplinas como a Geografia e a Sociologia, ressaltando a importância das dimensões humana, sócio-política, psicológica e cultural em sua abordagem. Diferenciou-se, assim, em vários e novos campos de atividade. Alguns deles encontram-se em estágio avançado de desenvolvimento teórico, já em outros a reflexão ainda é embrionária como a Ecolinguística.

A Ecolinguística vem ganhando amplitude no campo da Ecologia. Assim, tem sido como o "estudo das relações entre língua e meio ambiente", sendo que esse conceito é apresentado a partir das ideias de Einar Haugen, tido como pai da Ecolinguística, que define "ecology of language" e "language ecology" como "o estudo das interações entre 
qualquer língua dada e seu meio ambiente" (Couto 2007, p. 19). Neste aspecto, a autor entende que se deve partir inicialmente da compreensão do conceito de ecossistema entendido como o conjunto formado pelos seres vivos e seu meio ambiente considerando as interações ou interrelações que se dão entre os elementos componentes.

Essa noção de ecossistema remonta inicialmente a Tansley que já em 1935 definia-o como o sistema resultante da integração de todos os fatores vivos e não vivos do meio ambiente. $\mathrm{Na}$ perspectiva de Odum, um sistema ecológico ou ecossistema é qualquer unidade em que estejam incluídos todos os organismos, ao que ele denomina de comunidade, esta contida em uma determinada área onde ocorrem interações no meio físico resultando em um "fluxo de energia definindo claramente uma estrutura trófica, uma diversidade biótica e um ciclo de matérias" dentro dele (Couto 2007, p. 20).

De acordo com Negret (1982 p. 8-9), a institucionalização do conceito de ecossistema entendido como unidade funcional da natureza, como medida convencional, veio para facilitar sua investigação e a compreensão da estrutura-função das complexas inter-relações entre as comunidades vivas, considerando nelas as próprias interações das sociedades humanas com a natureza.

Enquanto isso, Couto (2009) afirma que um ecossistema linguístico é o lugar onde se insere uma língua e sua fala. Podendo ser reconhecido a partir da existência de um ecossistema linguístico que seria constituído pela língua (L), pela população que a fala $(\mathrm{P})$ e pelo território $(\mathrm{T})$, o lugar determinado onde ela é falada; esta totalidade passa a ser chamada de Ecologia Fundamental da Língua (EFL), também conhecida como comunidade. Se, em destaque for colocada a língua, tem-se que o povo e o território constituem o seu meio ambiente fundamental da língua. Nessa perspectiva, o meio ambiente da língua compreende, no entendimento de Sapir (apud Couto 2009, p. 28), todo o seu entorno caracterizado por seus aspectos geográficos, incluindo neste contexto a topografia, o clima, a vegetação, a fauna, os recursos minerais, bem como a base socioeconômica da vida humana. Neste sentido, o verdadeiro meio ambiente da língua é a sociedade que a usa como um de seus códigos (Haugen, 1972b, p. 325 apud Couto, 2007, p. 20). 


\section{Abordagem do tema}

A abordagem do tema fundamenta-se nos elementos da Ecolinguística, vista em Couto (2007, 2009), a qual se apropria como categorias de análises as situações de contato ou migração de indivíduos, grupos de indivíduos e de populações no espaço, podendo caracterizar a formação de ecossistemas linguísticos específicos como o que se estabelece na região de fronteira Brasil/ Venezuela. A análise é realizada a partir do material linguístico evocado nesse ambiente fronteiriço, levando-se em conta as interrelações que se estabelecem no território sob a perspectiva da linha francesa da Análise do Discurso, Maingueneau (2008), que constitui uma dimensão discursiva, parte da identidade do sujeito observada em seu posicionamento discursivo.

Nessa perspectiva, o ambiente ecolinguístico em que o discurso é produzido, considerando a situação de contato e território, irá influenciar o sentido construído do discurso, levando em conta sua materialidade histórica. Isto porque as representações sociais

(...) são sempre complexas e necessariamente inscritas dentro de um 'referencial de um pensamento preexistente' sempre dependentes, por conseguinte, de sistemas de crença ancorados em valores, tradições e imagens do mundo e da existência. Elas são, sobretudo, um permanente trabalho social, no e através do discurso, de tal modo que cada novo fenômeno pode sempre ser reincorporado dentro de modelos explicativos e justificativos que são familiares e, consequentemente, aceitáveis (Moscovici, 2007, p. 216).

De outra forma, observa-se que não há representações sociais sem linguagem, do mesmo modo que sem elas não há sociedade (Moscovici, 2007, p. 219). Neste sentido, para analisar o discurso do sujeito em sociedade torna-se necessário enxergar a linguagem como instrumento construído na interface da realidade natural, mentalpsicológica e social do homem. "Essa mediação, que é o discurso, torna possível tanto a permanência e a continuidade quanto o deslocamento 
e a transformação do homem e da realidade em que ele vive" (Orlandi, 2009, p. 15).

Assim, num determinado ecossistema linguístico, em que se dá a cena do cotidiano, fica evidente que qualquer sujeito está assim "cercado, tanto individualmente como coletivamente, por palavras, ideias e imagens que penetram nossos olhos, nossos ouvidos e nossa mente, quer queiramos quer não e que nos atingem, sem que saibamos" (Moscovici, 2007, p. 33).

\section{Os colaboradores entrevistados}

Os colaboradores desta pesquisa são constituídos por quatro sujeitos venezuelanos habitantes em Santa Elena de Uairén e alunos do curso de PLE, conforme dados sociolinguísticos apresentados na Tabela 1, a seguir:

\begin{tabular}{|c|c|c|c|c|c|c|}
\hline \multicolumn{6}{|c|}{ Tabela 1: Dados Sociolinguísticos dos sujeitos da fronteira } \\
\hline $\begin{array}{c}\text { SUJEITO } \\
\text { ENUNCIADOR } \\
\text { - SE }\end{array}$ & IDADE & SEXO & PROFISSÃo & $\begin{array}{c}\text { TEMPO NO } \\
\text { MUNICIPIO DE } \\
\text { SANTA ELENA } \\
\text { DE UIARÉN }\end{array}$ & $\begin{array}{c}\text { LÍNGUA DA } \\
\text { ENTREVISTA }\end{array}$ \\
\hline SE- 1 & Raquel & 20 & $\mathrm{~F}$ & $\begin{array}{c}\text { Serviço } \\
\text { Privado- } \\
\text { Atendente }\end{array}$ & 20 anos & Português \\
\hline SE-2 & Maria & 50 & $\mathrm{~F}$ & $\begin{array}{c}\text { Serviço } \\
\text { Público - } \\
\text { Turismo }\end{array}$ & 50 anos & Português \\
\hline SE-3 & Salomão & 55 & $\mathrm{M}$ & $\begin{array}{c}\text { Serviço } \\
\text { Público- } \\
\text { Professor }\end{array}$ & 26 anos & Espanhol \\
\hline SE-4 & Tomé & 27 & $\mathrm{M}$ & $\begin{array}{c}\text { Serviço } \\
\text { Privado- } \\
\text { Músico }\end{array}$ & 6 meses & Espanhol \\
\hline
\end{tabular}

* Os nomes dos moradores da fronteira apresentados, nesta pesquisa, são fictícios.

Fonte: Dados da pesquisa em junho de 2011 


\section{Análise da situação de contato no ambiente fronteiriço}

Segundo Couto (2009, p. 49-54) as situações de contato de povos e línguas em determinado território, podem ser analisadas a partir de quatro situações. Em nossa análise e caracterização da fronteira Brasil/Venezuela, identificamos duas dessas quatro situações de contato. A primeira corresponde ao momento historicamente marcado pelo processo de colonização iniciado a partir das grandes navegações, quando os europeus aportaram no continente sul americano no século XV. Esse contexto corresponde no modelo de Couto (2009, p.52) a uma situação em que " $\mathrm{PL}_{1}$, o povo mais forte política, econômica e militarmente e de prestígio se desloca para o território $\mathrm{T}_{2}$, mais fraco".

Já a segunda situação de contato, é mais contemporânea e se caracteriza como parte de um processo histórico que culmina com a formação embrionária da fronteira entre os dois países. Esse segundo contexto corresponde no modelo de Couto (2009, p. 54) à situação de contato em que "membros de $\mathrm{PL}_{1}$ se deslocam, temporária ou sazonalmente, para o território de $\mathrm{PL}_{2}$ e/ou membros de $\mathrm{PL}_{2}$ se deslocam para o território de $\mathrm{PL}_{1}$ ".

As relações estabelecidas hoje são justificadas pela história das relações históricas entre os povos. É possível perceber que o processo de ocupação e formação do espaço territorial de Roraima nasce com as expedições europeias à região do Rio Branco, iniciadas na virada dos séculos XVII e XVIII, representadas por holandeses, espanhóis e portugueses com a presença de forças militares e religiosas. Coube, porém, aos portugueses a ocupação efetiva deste espaço amazônico do lado Brasileiro e aos espanhóis do lado venezuelano.

\section{Ecossistema linguístico "provisional”: uma proposta}

As relações nessa região se deram principalmente pelas atividades comerciais, dinamizadas durante o século XI, especialmente nas suas últimas décadas, resultado da atividade mineradora de caucho, culminou com o fortalecimento e organização da ocupação dos 
territórios. O comércio crescia em função da presença de exploradores interessados em produtos para venda no continente europeu. Há de se manter a ideia de que com a penetração hispânica se iniciou a estruturação do espaço regional, já que a criação de povoados serviu para organizar as comunicações e troca de mercadorias na região na região (Boadas, 1983, p. 88).

As transformações e intercâmbios que ocorrem e mantêm em comunicação permanente diferentes ecossistemas dificultam a determinação dos limites exatos entre eles. Ora, os povos que se encontram em um espaço ainda não estabelecido totalmente, circulando entre os dois ecossistemas (Brasil/Venezuela), também ainda não se encontram estabelecidos e, portanto, ainda não definidos. Assim, a delimitação destes ecossistemas, como unidade funcional de investigação, é ainda puramente convencional. Eles vão sendo definidos de acordo com a área de interesses do investigador (Negret 1982, p. 8). Diz-se, por exemplo, que um ecossistema pode ser uma floresta inteira ou pode estar representado por uma simples bromélia, "em cujo receptáculo formado pelas folhas acumula-se água permitindo o desenvolvimento de algas fotossintetizantes seguidas de toda uma complexa fauna de protozoários e microinvertebrados" (Branco 1987, p. 20). Desse modo, esses ecossistemas podem ser considerados como sistemas abertos, sendo eles influenciados por um conjunto de fatores que são determinantes dos posicionamentos discursivos dos seus sujeitos. Um exemplo típico do ecossistema em questão é o que pode ser encontrado na interface dos dois lados da fronteira Brasil/Venezuela caracterizando um ambiente onde se verificam fortes relações de comércio, educação, amizade dentre outros tipos, construídas no decorrer do processo de formação da fronteira a partir de especificidades de ordem histórica e política iniciada durante o período em que se foram fixando as populações nessa região.

Acredita-se assim, ser possível o desenho de um tipo de ecossistema linguístico particular, situado na confluência dos dois ecossistemas Fundamentais da Língua $\mathrm{EFL}_{1}$ e $\mathrm{EFL}_{2}$, representados respectivamente pelo Brasil e Venezuela, envolvendo as comunidades 
de Santa Elena de Uairén e Pacaraima especificamente, que, embora guardem suas especificidades e diferenças em virtude dos modelos de gestão político-administrativa dos países de que fazem parte, constituem por assim dizer, um único ecossistema que se influenciam mutuamente e se atendem de forma recíproca, comunicando-se através das línguas características do luga, o que, por princípio, poderia ser denominado de ecossistema linguístico "provisional". Já que cada um dos lados dessa fronteira se provisiona mutuamente por meio do atendimento das suas demandas, conforme verificado na figura 1: Diagrama do Ecossistema Linguístico Provisional de contato Brasil/Venezuela (ALVES DA SILVA, 2012).

A conformação de um ecossistema, com base nas características apontadas, caracterizando o Diagrama do Ecossistema Linguístico "provisional" de contato Brasil/Venezuela, modelo adaptado de Couto (2009), demonstra assim, as relações que se estabelecem entre os dois ecossistemas, onde, de um lado, tem-se o ecossistema brasileiro e, de outro, o ecossistema venezuelano. O diagrama demonstra que, dependendo do comportamento das forças econômicas e políticas estabelecidas nesse ecossistema, elas irão afetar de alguma forma, a situação de contato em "la línea" de fronteira, podendo beneficiar mais ou menos um ou outro lado, em dado momento. Couto (2009, p. 55) aponta seis fatores que influenciam no resultado do contato, que podem ser de diferentes naturezas e classificados como sendo: a quantidade de pessoas em interação; o tempo de permanência no território; a intensidade do contato; as atitudes de resistência e não resistência entre as culturas; a semelhança/dessemelhança tipológica das línguas em questão, sendo que o todo é afetado pela conjuntura e incidência do poder político-econômico-militar do Estado Nação. Observe-se a Figura 1: Diagrama do Ecossistema Linguístico Provisional de contato Brasil/Venezuela apresentada a seguir. 


\section{Ecossistema linguístico "provisional"Brasil/Venezuela: uma proposta}

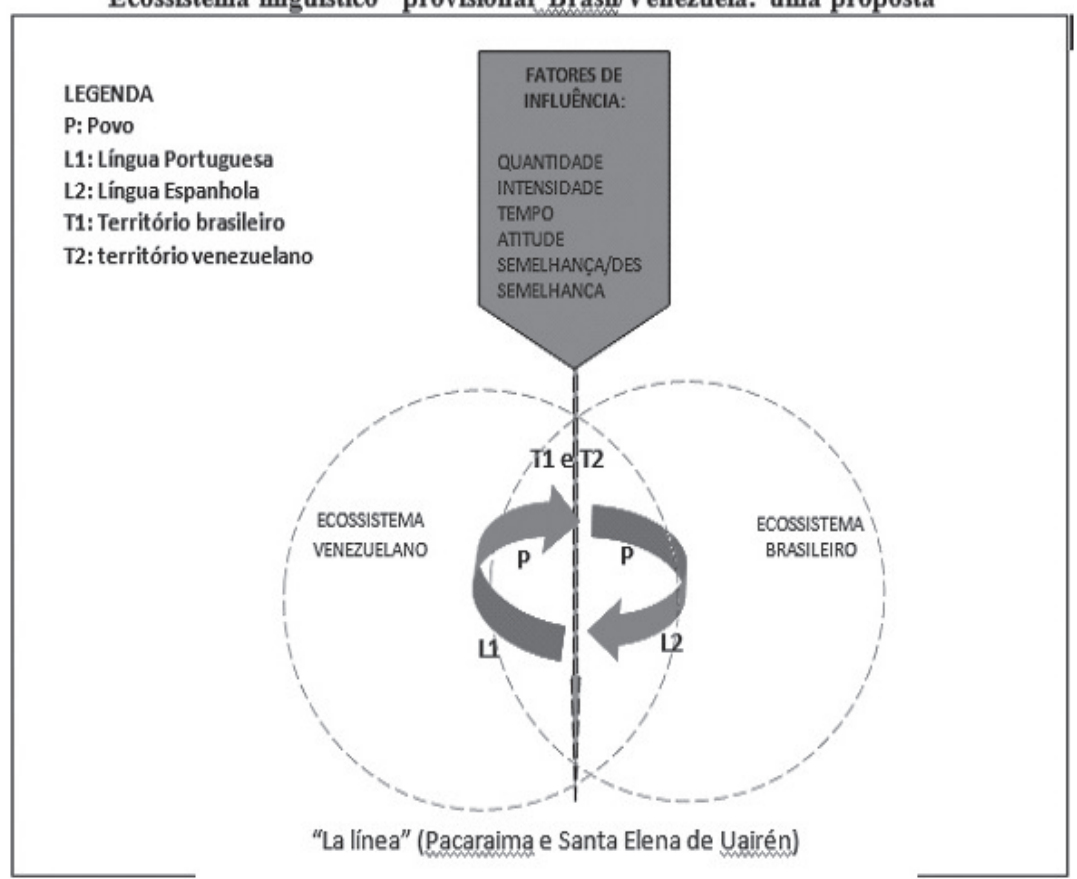

Figura 1: Diagrama do Ecossistema Linguístico Provisional de contato Brasil/Venezuela

(Fonte: Alves-da-Silva, 2012)

Como pode ser verificado, esses ecossistemas encontramse imbricados um no outro, dando lugar ao surgimento de um ecossistema constituído por uma totalidade representada pelos municípios fronteiriços de Pacaraima e Santa Elena de Uairén. Corroborando essas circunstâncias, Santa Elena de Uairén foi declarada "puerto libre" em 1999, dinamizando, assim o tráfego de mercadorias, de bens imateriais e simbólicos, provocando de certa forma a recuperação da economia local, e aproximando cada vez mais os povos que ali se encontram. Se por um lado Santa Elena de Uairén possui uma rede de comércio e serviços bastante significativa, como farmácias, restaurantes, telefonia, supermercados, pizzarias, hotéis, e postos de gasolina, inclusive uma que atende somente a 
brasileiros, o lado brasileiro (em Pacaraima) não existem postos de gasolina, o que incentiva cada vez mais a presença de brasileiros em Santa Elena de Uairén.

Todos esses fatores, agregados ao potencial energético proporciona um estreitamento das relações entre Brasil/Venezuela, a exemplo do acordo estabelecido em torno do Linhão de Guri que está localizado no município de Santa Elena de Uairén, que fornece energia para o estado de Roraima. Nesta confluência de interesses de ambos os lados da fronteira, representada por uma linha imaginária, os povos mantêm relações pessoais e comerciais, sendo que ali se estabelece, de forma efetiva, uma relação de interesses comuns, como bem afirma Behares (1996, p. 25) para quem "la frontera no es una línea que divide A de B, sino un espacio que contiene C".

Nesse ponto, é possível considerar que os limites de um ecossistema de fronteira são conformados por relações marcadas por influências recíprocas, fruto de todo um contexto (sócio-histórico, político e econômico dos países vizinhos), que oscila permanentemente com avanços e recuos, sobretudo, econômico, relacionados ao valor das respectivas moedas nacionais. Desta dinâmica, surge o ecossistema linguístico "provisional", como substrato dessas relações, nas quais se mesclam povo, território e língua num ambiente que podemos definir como um subsistema ecolinguístico localizado na interface dos dois grandes ecossistemas, o brasileiro e o venezuelano.

\section{Considerações finais}

As faixas limítrofes entre dois países, particularmente aquelas que não apresentam acidentes geográficos ou forças militares obstaculizando uma relação de vizinhança entre suas populações, conformam espaços de relacionamento das mais diversas índoles entre seus povos. Embora normalmente as regiões fronteiriças do norte brasileiro configurem-se como locais periféricos, afastados dos centros de influência política e econômica nacional, há uma peculiar e estreita relação econômica, social e cultural nesses ambientes. Nesse 
espaço singular, onde se misturam falas de diferentes línguas é gerado um ecossistema linguístico instituído na interface dos dois lados da fronteira Brasil/Venezuela, bem como das fronteiras regionais e transnacionais relacionadas a etnias e culturas afetadas pelo processo histórico da colonização.

Nesse ambiente, constituído pela totalidade formada por um povo, um território e uma língua, ou seja, o que Couto denomina de comunidade. No caso específico da situação de 'la línea' de fronteira, se constata a constituição de um ecossistema no qual os povos historicamente implicados e suas respectivas línguas convivem em permanente simbiose, uns se beneficiando do outro, de forma recíproca. Essa propriedade simbiótica é considerada como fundamental para a compreensão das relações advinda do resultado das relações estabelecidas na região.

O momento socioeconômico dessa região impulsiona o posicionamento do sujeito que ora se enuncia como parte integrante da comunidade linguística de Santa Elena de Uairén , ora como parte integrante de um "lugar que é comum" a brasileiros e venezuelanos. Quando se enuncia como parte de um "lugar comum", o sujeito se apropria do pronome "nós/a gente" e tem como referente "brasileiros e venezuelanos", o que parece construir discursivamente um lugar comum para ambos os povos que estão em permanente contato em "la línea". Os povos europeus mais fortes econômica, política e militarmente subjugam os povos indígenas, apesar da diferença numérica das populações e graças à tecnológica militar dos europeus, que mesmo em menor número se impõem na região. Suas respectivas línguas em decorrência do poder político e militar tornamse na região conhecida hoje como fronteira Brasil/Venezuela, as línguas oficiais dos respectivos países e as variedade de maior prestígio em detrimento das línguas indígenas, nesta pesquisa, $\mathrm{PL}_{3}, \mathrm{PL}_{4}, \mathrm{PL}_{5}$ (Ingaricó, Wapixana, Wai Wai, Pemón), de acordo com os sujeitos implicados em cada situação de contato.

O contato atual entre esses povos é influenciado principalmente pelo fator intensidade em função da mobilidade que se dá na região e pelo comércio, caracterizando o surgimento de um ecossistema 
específico intitulado Provisional, porque é caracterizado pelo atendimento mútuo de demandas desses povos.

Recebido: 20/09/2013

Aceito: 07/03/2013

profivonesilva@gmail.com

\section{Referências bibliográficas}

ALVES DA SILVA, Maria Ivone. A construção do ethos fronteiriço Brasil/ Venezuela em ambiente ecolinguístico. Círculo Fluminense de Estudos Filológicos e Linguísticos Revista Philologus, Ano 17, nº 51, set./dez.2011 Suplemento. Rio de Janeiro: CiFEFiL, 2011, p. 484-491.

BEHARES, Luís M. Historia y discurso sobre educación en zonas de frontera. In: TRINDADE, Aldema M., BEHARES, Luis E. (org.), Fronteiras, educação, integração, págs. 25-34. Universidade Federal de Santa Maria (UFSM), Santa Maria, 1996,

- O ethos em "la línea" de fronteira Brasil/Venezuela: ambiente ecolinguístico e redes sociais. Dissertação de Mestrado-UFRJ, 2012.

BOADAS, Antonio Rafael. Geografia del amazonas venezolano. Ariel-seix Barral venozelano. Caracas, 1983.

BRANCO, Samuel Murgel. Elementos de ciências do ambiente. $2^{\text {a }}$ Ed. São Paulo. Ed. Ceterg. 1987.

COUTO, H. H. do. Ecolinguística: estudo das relações entre língua e meio ambiente. Brasília. Thesaurus. 2007.

Linguística, ecologia e ecolinguística. São Paulo. Contexto. 2009.

DAJOZ, Roger. Ecologia Geral. Petrópolis-RJ. 4 ed. Vozes, 1983.

FREITAS, Aimberê. Geografia e história de Roraima. Manaus: Grafima, 1991.

MAINGUENEAU, D. A propósito do ethos. In: Motta, A. R. \& Salgado, L. (orgs.). Ethos discursivo. São Paulo: Contexto, 2008.

MARTIN, André Roberto. Fronteiras e nações. Contexto. São Paulo. 1992

MOSCOVICI, Serge. Representações sociais: investigação em psicologia social. Trad. Pedrinho A. Guareschi. Petrópolis, RJ: Vozes, 2007 
NEGRET, Rafael. Ecossistema: Unidade básica para o planejamento da ocupação territorial; ecologioa e desenvolvimento. Rio de Janeiro. Ed. FGV, 1982.

ORLANDI, Eni. Análise do discurso: Princípios e procedimentos. $8^{\mathrm{a}}$ Ed., Campinas, São Paulo, Pontes, 2009.

RODRIGUES, Francilene. Migração transfronteiriça na Venezuela. Estudos Avançados-20, 2006.

Disponível em http://www.scielo.br/pdf/ea/v20n57/a15v2057.pdf. Acesso em 07.Mai.2011. 